\title{
Analysis of the Efficiency of Spanish Soccer League Players (2009/10) Using the Metafrontier Approach
}

\author{
RAFAEL CABALLERO FERNÁNDEZ \\ Departamento Economía Aplicada (Matemáticas), UNIVERSIDAD DE MÁLAGA, \\ ESPAÑA. E-mail: Rafael.Caballero@uma.es
}

TRINIDAD GÓMEZ NÚÑEZ

Departamento Economía Aplicada (Matemáticas), UNIVERSIDAD DE MÁLAGA, ESPAÑA. E-mail: trinidad@uma.es

\section{RAMÓN SALA GARRIDO}

Departamento Economía Aplicada (Matemáticas), UNIVERSIDAD DE VALENCIA, ESPAÑN. E-mail: sala@uv.es

\begin{abstract}
This paper analyses the efficiency of players in the Spanish Soccer League for the 2009/2010 season using a metafrontier version of data envelopment analysis (DEA) methodology. It is possible to apply a metafrontier approach if separate frontiers can be identified for different groups in the data set. In our case, we divide the sample of players into three groups, according to the playing position within a team, because different positions define different behaviours (technologies). These behaviours are compared against each other and globally.
\end{abstract}

Keywords: DEA, Metafrontier, Efficiency, Soccer Players.

\section{Análisis de la eficiencia de los jugadores de fútbol de la Liga Española (2009/10) mediante el enfoque Metafrontier}

\section{RESUMEN}

En este trabajo se analiza la eficiencia de los jugadores en la Liga Española de Fútbol para la temporada 2009/2010 con la metodología del Análisis Envolvente de Datos (DEA) pero en la una versión metafrontera. Es posible aplicar el enfoque de la metafrontera si para diferentes grupos del conjunto de datos es posible construir fronteras particulares para cada uno de ellos. En nuestro caso, dividimos la muestra de jugadores en tres grupos, de acuerdo con la posición de juego dentro de un equipo, debido a las diferentes posiciones definir comportamientos diferentes tecnologías). Estos comportamientos se comparan entre sí y globalmente

Palabras clave: DEA, Metafrontera, eficiencia, futbolistas.

JEL Clasification: C61, L83

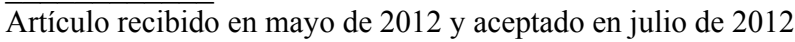

Artículo disponible en versión electrónica en la página www.revista-eea.net, ref. ə-30215 


\section{INTRODUCTION}

The most popular sport in Spain is soccer, although other sports such as basketball, motorcycling, and tennis are also growing in popularity because of recent successes by Spanish participants.

This paper focuses in the Spanish soccer league season 2009/10. The season was interesting because of the competition between FC Barcelona and Real Madrid CF that resulted in the greatest number of points ever won in the league (99 points for FC Barcelona), and the championship was only decided on the final day of competition. As a result, the performance of the teams and players was widely discussed by the media and soccer fans.

Analyses about these performances can be based on team ranking in the league. However, no such ranking exists in the case of individual players; and only the subjective opinions of sports commentators and journalists enable an evaluation to be made of the performance of players in each match.

As noted by Tiedemann et al. (2011) these classifications can be criticised on at least two aspects: firstly, it is often the case that only attacking players are considered without paying attention to the performance of the Midfield or Defence. Secondly, such classifications are subjective and the assessments of performances differ because there is often much disagreement among experts.

The aim of this work is to present an evaluation of performance and player behaviour based on a methodology that uses objective data. Although it may seem that such research could only interest fans and journalists, it is also interesting for the managers of soccer clubs and the players themselves. For teams and their managements, this information can reveal how players are performing and this, in turn, is a major influence on the market value (Lucifora and Simmons, 2003) of players from different teams, and is also of interest when setting payment schemes based on performance. The players themselves will want to know which benchmarks players to use as a comparison for improving their own game and may also use the information to support claims for performance-linked salary increases (on the understanding that such information will only be used by those players with good evaluations, and that players will not ask for pay cuts if performance is disappointing).

There have been many studies regarding the analysis of efficiency in soccer teams and the performance of athletes, sports teams, and their managers or coaches. Dawson et al. (2000) estimated the technical efficiency scores from a panel of soccer coaches - using as inputs a set of variables that represent the 'quality' of a team, and the proportion of games won as an output. The study uses data from football teams and applies stochastic frontier analysis to estimate a frontier that represents efficient combinations of inputs and outputs. 
Other studies have used data envelopment analysis (DEA) to show that the efficiency scores of soccer teams are highly correlated with league success. Efficiency can be measured only with respect to an 'average team' but not in relation to maximum efficiency (Kern and Süssmuth, 2005). The efficiency of professional soccer clubs in Spain has been estimated in Espitia-Escuer and García-Cebrián (2006); González-Gómez and Picazo-Tadeo (2010); SalaGarrido et al. (2009), among others. Espitia-Escuer and García-Cebrián (2006) applied the DEA method to evaluate the performance of teams between 1998 and 2005. Comparing the results obtained by soccer teams with the results the teams should have obtained on the basis of their potential, the study concludes that the final team position in the league depends more on the efficient use of resources than on potential. Sala-Garrido et al. (2009) analysed the efficiency scores of teams from the 2000/2001 to 2007/08 seasons in terms of their offensive power and defensive performance. Boscá et al. (2009) compared and tested the technical efficiency of soccer clubs in Italy and Spain during the 2000/2001 to 2002/03 seasons. Their analysis was also based on DEA models. The authors concluded that the Spanish league is considerably more consistent and competitive than the Italian league. The authors also pointed out that to obtain a good ranking in the Italian league it is much more important to improve the effectiveness of the defensive game than the offensive game; while the recommendation for the Spanish league is a combined strategy of improved offensive efficiency at home and increased defensive efficiency when playing away.

In contrast, few studies have focused on soccer players individually. Alp (2006) used DEA to evaluate the performance of goalkeepers in the World Cup 2002. Papahristodoulou (2007) evaluated the individual performance of forwards by analysing the techniques and efficiency of the scorers in the UEFA Champions League using statistics published by the UEFA. Data on minutes played, free kicks conceded, and offsides were used as inputs; while data on goals scored, assists, shots on goal, and free kicks given were used as outputs. However, the author points out that due to software limitations, only forwards who had scored two or more goals were assessed. Recently Tiedemann et al. (2011) used metafrontier calculations to analyse the behaviour of field players in the German Bundesliga during the 2002/03 to 2008/09 seasons. They included one input (playing time) and three outputs (Goals, Assits, Tackle ratio and Pass completion ratio) for all three playing position considered (Defenders, Midfielders and Forwards). In their analysis, they found close relationships between efficiency scores and observed sporting success. In the current paper, we follow a similar approach, but we incorporate specific outputs to each playing position for a better characterizing of these ones. Moreover we have also compared the efficiency of the Spanish and foreign players and we have analysed the correlation between the number of efficient players per team and the points won by each team. 
The main aim of this paper is to assess the efficiency of the Defenders, Midfielders and Forwards of the Spanish soccer league for the season 2009/10. In doing so, the DEA metafrontier model has been applied to a sample of 411 players from 20 Spanish teams. In a second step, players have been classified according several categories. For others applications of DEA methodology, see Riera et al (2011).

The paper is structured as follows: Section 2 describes the theoretical basis of the model. A description of the data and variables used is provided in Section 3 , followed by the main results in Section 4. Finally, Section 5 presents some conclusions based on our analysis.

\section{METHODOLOGY}

In soccer, as in most team sports, the tasks for each player vary according to their position on the field. Defenders prevent the opposing team from scoring, while Forwards must score so that their teams can win the game and league points. Midfielders have a dual mission: firstly, to support defenders in preventing the opponent from scoring; and secondly, to help Forwards score against the opposition. Thus, the whole sample of players can be divided into three heterogeneous groups according to their position in the team: Defenders, Forwards and Midfielders. According to the metafrontier approach, each player is evaluated against two different frontiers: one based only on players from the group to which he belongs and other based on units from all the different groups in the sample.

In this section, we explain the concept of metafrontier and the group frontiers in terms of inputs and outputs, using production theory and the concept of distance functions. In this task, we follow the approach of O'Donnell et al. (2008) and Sala-Garrido et al. (2011).

The use of the metafrontier methodology is possible if separate frontiers can be identified for different groups in the data set. Here, we suppose that there are $K$ groups $(K>1)$ within the whole set of observations that operate with different technologies. Let $\boldsymbol{x}$ and $\boldsymbol{y}$ be non-negative input and output vectors of dimensions $m \times 1$ and $s \times 1$, respectively. The technology of group $k(k=1,2, \ldots, K)$ can be defined as all the combinations of inputs and outputs available to a unit in that group:

$$
T^{k}=\left\{(\boldsymbol{x}, \boldsymbol{y}) \in R_{+}^{m+s} / \boldsymbol{x} \text { can produce } \boldsymbol{y}, \text { in group } k\right\}
$$

These technology groups (sub-technologies) can also be represented by the corresponding groups of outputs sets:

$$
P^{k}(\boldsymbol{x})=\left\{\boldsymbol{y}:(\boldsymbol{x}, \boldsymbol{y}) \in T^{k}\right\} \quad k=1,2, \ldots, K
$$


We term the boundary of each output set as the group frontier. These group frontiers are enveloped by a global frontier. Thus, if a particular output $\boldsymbol{y}$ can be produced using an input vector $\boldsymbol{x}$, in a group, then $(\boldsymbol{x}, \boldsymbol{y})$ are included in the set $T$, that is:

$$
T=\left\{(\boldsymbol{x}, \boldsymbol{y}) \in R_{+}^{m+s} / \boldsymbol{x} \text { can produce } \boldsymbol{y} \text { in some group } T^{k}(k=1,2, \ldots, K)\right\}
$$

Consequently, $T=$ Convex Hull $\left\{T^{1} \cup T^{2} \cup \ldots \cup T^{K}\right\}$, and the output set associated with $T$ is defined by:

$$
P(\boldsymbol{x})=\{\boldsymbol{y}:(\boldsymbol{x}, \boldsymbol{y}) \in T\}
$$

We name the boundary of this output set as the output metafrontier.

As the main objective of our work is to measure efficiency, it is worthwhile representing the sub-technology sets using output distance functions:

$$
D^{k}(\boldsymbol{x}, \boldsymbol{y})=\inf _{\theta}\left\{\theta>0:(\boldsymbol{y} / \theta) \in P^{k}(\boldsymbol{x})\right\} \quad k=1,2, \ldots, K
$$

and the technology set by output metadistance function:

$$
D(\boldsymbol{x}, \boldsymbol{y})=\inf _{\theta}\{\theta>0:(\boldsymbol{y} / \theta) \in P(\boldsymbol{x})\}
$$

These functions provide the maximum amount for which a unit decision making (DMU) can radially increase its output vector, given an input vector.

If the output sets $P^{k}(x)(k=1,2, \ldots, K)$ and $P(x)$ satisfy the properties of regularity (Färe and Primont (1995)), then the distance functions $D^{k}(x, y)(k=1$, $2, \ldots, K)$ and $D(x, y)$ also satisfy the usual regularity properties.

To estimate the group frontiers and the metafrontier, an output-orientated DEA model with variable returns (VRS) is used (see Bonilla et al., 2002). Thus, we obtain a measurement of Pure Technical Efficiency (PTE), uncontaminated by problems of scale which could occur in the CCR model (constant returns to scale). We have chosen an output orientation since our aim is to determinate whether the players, considering their position in the team, can improve their output, given their input values. Therefore, the problem to solve for the group $k$ $(k=1,2, \ldots, K)$ is: 
$\operatorname{Max} \phi^{k}$

s.a:

$$
\begin{cases}\sum_{j=1}^{n_{k}} \lambda_{j} x_{i j} \leq x_{i 0} & i=1, \ldots m \\ \sum_{j=1}^{n_{k}} \lambda_{j} y_{r j} \geq \phi^{k} & y_{r 0} \quad r=1, \ldots S \\ \sum_{j=1}^{n_{k}} \lambda_{j}=1 & \\ \lambda_{j} \geq 0 & j=1, \ldots n_{k}\end{cases}
$$

Where $x_{i j}$ e $y_{r j}$ represent, respectively, the amount of the input $i$ ( $i=1$, $2, \ldots, m)$ and output $r(r=1,2, \ldots, s)$ for the decision unit $j$ (DMUj) $(j=1,2, \ldots$, $n_{k}$ ), with $x_{i 0}$ and $y_{i 0}$ corresponding to the analysed DMU; $n_{k}$ is the number of units in group $k ; \phi^{k}$ is a scalar that verifies $1 / \phi^{k}$, so that $1 / \phi^{k} \in[0,1]$, and it is the output efficiency measure given by $D^{k}(\boldsymbol{x}, \boldsymbol{y})(k=1,2, \ldots, K)$. The evaluated unit is efficient, with respect to the frontier of its group $k$, if $\phi^{k}=1$ and the slacks of all the constraints in the model [1] are zero. For example, $D^{k}$ $(x, y)=0.7$ indicates that the output obtained is $70 \%$ of maximum output that could be produced using a vector of $\boldsymbol{x}$ inputs, within the $k$ technological group.

This process is repeated for every unit in the group $k$, and for each sub-technology. We proceed similarly for the construction of the metafrontier; but the units to consider in this case are all of the DMUs of the different sub-technologies. The number of units is given by the sum of the number of units in each group, i.e., $n=n_{1}+n_{2}+\ldots+n_{K}$.

The model to be applied is the same than previously [1]. In this case, the metaefficiency score $1 / \phi^{*}$ is lower than the scores of the different subtechnologies $1 / \phi^{k}$, because the constraints of the problem [1] are a subset of the constraints of the metafrontier problem. In other words, the metafrontier envelopes all the sub-technologies. This fact is illustrated in Figure 1, where we represent a problem of a single input and a single output with three groups. 
Figure 1

Graphical representation of a metafrontier

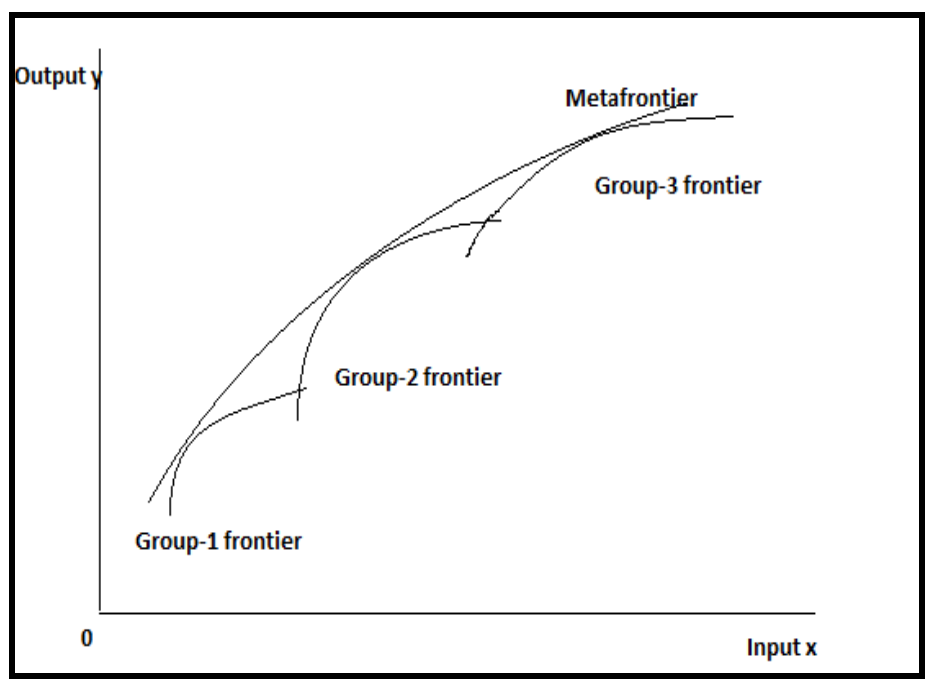

Source: Own elaboration.

When a strict inequality exists between the distance function of the $k$ group and the metafrontier, we can obtain a measure of the proximity (gap) of the group- $k$ frontier to the metafrontier. In this way, the output-oriented metatechnology ratio for group $k$ can be defined as:

$$
\operatorname{MTR}^{k}=\frac{D(\boldsymbol{x}, \boldsymbol{y})}{D^{k}(\boldsymbol{x}, \boldsymbol{y})}=\frac{\phi^{k}}{\phi^{*}} \leq 1
$$

This implies that the metaefficiency score of a unit can be decomposed in the following way:

$$
\frac{1}{\phi^{*}}=\frac{1}{\phi^{k}} M T R^{k}
$$

\section{DATA}

A soccer team consists of a goalkeeper and ten field players. Although there are many options for game according to the classification made by GECASPORT, the field players are usually divided into Defenders, Midfielders, and Forwards.

In our study, we have selected field players, and the goalkeepers were excluded because of their special behaviour. Only league players who had played for more than 200 minutes (a time period equalling at least two full games) were 
considered as this filter avoids high performance players who may have only played for a few minutes.

In total we selected 149 Defenders, 175 Midfielders, and 87 Forwards from the 20 teams in the first Spanish division. Given that a joint analysis must be made to obtain the envelope of the different technological frontiers and metafrontiers, we have selected the following variables:

As input: minutes played (with the prerequisite of having played a minimum of 200 minutes).

As outputs for all players, we have selected six variables representing the activity of each of the various positions, i.e., two variables for each technologies:

- Shots (Forwards)

- Goals (Forwards)

- Assists (Midfielders)

- Interruptions of opposition plays (Midfielders)

- Clearings (Defenders)

- Ratio of passes, i.e.: the ratio of good passes from the total number of passes made (Defenders), because defenders are the least 'risky' and therefore their ratios are the best.

Table 1

Descriptive statistics of the data

\begin{tabular}{|l|c|c|c|c|}
\cline { 2 - 5 } & Position & DEF & MID & FOR \\
\cline { 2 - 5 } & Number Players & 149 & 175 & 87 \\
\hline \multirow{2}{*}{ Minuts } & Mean & 1780.72 & 1701.10 & 1581.49 \\
\cline { 2 - 5 } & $S D$ & 861.19 & 840.63 & 878.96 \\
\hline \multirow{2}{*}{ Shots } & Mean & 8.55 & 24.37 & 46.08 \\
\hline \multirow{2}{*}{ Assits } & $S D$ & 8.56 & 19.30 & 37.76 \\
\hline \multirow{2}{*}{ Goals } & $M e a n$ & 7.04 & 19.86 & 19.55 \\
\cline { 2 - 5 } & $S D$ & 8.84 & 17.12 & 14.76 \\
\hline \multirow{2}{*}{ Clearings } & $M e a n$ & 0.78 & 2.01 & 6.14 \\
\cline { 2 - 5 } & $S D$ & 1.11 & 2.46 & 6.44 \\
\hline \multirow{2}{*}{ Interrupts } & $M e a n$ & 319.45 & 175.09 & 63.13 \\
\cline { 2 - 5 } & $S D$ & 173.99 & 131.62 & 43.56 \\
\hline \multirow{2}{*}{ R. Passes } & $M e a n$ & 1705.46 & 2061.29 & 1994.61 \\
\cline { 2 - 5 } & $S D$ & 758.83 & 725.28 & 713.95 \\
\hline
\end{tabular}

Source: Own elaboration based on data from GECAsport. 
Table 1 summarises statistics for these actions. Clearly, not all the 411 players have scored in the league. Therefore, a convention has been established when the score of an action is zero, because in DEA models are most convenient all the dates must be positives. For this, we include a small number as lower bound, and thereby maintaining the assumption that all data input is greater than zero. This substitution does not alter the analysis.

To test that different players use different 'technologies' a Kruskal-Wallis test was made to see whether the actions rank players according to their position. The obtained results (see Table 2) reveal the independence of the player positions.

Table 2

Kruskal-Wallis test statistics for differences in the playing positions

\begin{tabular}{|c|c|c|c|c|c|c|}
\hline & Shots & Assists & Goals & Clearing & Interrupts & $\begin{array}{c}\text { R. } \\
\text { Passes }\end{array}$ \\
\hline$p$-value & 0.00 & 0.00 & 0.00 & 0.00 & 0.00 & 0.00 \\
\hline
\end{tabular}

Source: Own elaboration.

\section{RESULTS AND DISCUSSION}

By applying the model [1] the following results are obtained:

Table 3

Efficiency results in each position

\begin{tabular}{|l|c|c|c|}
\hline \multicolumn{1}{|c|}{ Position } & Number Eff & $\%$ & Mean Score \\
\hline DEFENDER & 37 & 24.8 & 0.9378 \\
\hline MIDFIELDERS & 50 & 28.6 & 0.9403 \\
\hline FORWARDS & 36 & 41.4 & 0.9408 \\
\hline
\end{tabular}

Source: Own elaboration.

In each of the positions there is a different percentage of efficient players (number of efficient players (Number Eff) on the total of players). We can see in Table 3 that almost half of the Forwards are efficient. The scores obtained are relatively high and this is because the VRS methodology is very close to the frontier of each of the DMUs. When we calculate the metafrontier, the results change significantly; and, within the metafrontier each group has the following results: 
Table 4

Efficiency results within the metafrontier

\begin{tabular}{|l|c|c|c|}
\hline \multicolumn{1}{|c|}{ Position } & Number Eff & $\%$ & Mean Score \\
\hline DEFENDER & 24 & 16.1 & 0.9196 \\
\hline MIDFIELDERS & 25 & 14.3 & 0.9200 \\
\hline FORWARDS & 17 & 19.5 & 0.9189 \\
\hline ALL PLAYERS & 66 & 16.1 & 0.9196 \\
\hline
\end{tabular}

Source: Own elaboration.

As expected, metafrontier efficiency is lower than the efficiencies of the different positions. Moreover, the number of efficient units in each of the three positions has also significantly decreased, and so now only 1 in 5 Forwards are efficient, as can be observed in Table 4.

If we compare the number of efficient players on the technological frontier of each of the positions with the metafrontier, the reduction in efficient players is greater among the Forwards (from 36 to $17 ; 47.2 \%$ ) compared to the Defenders (from 37 to 24; 64.9\%) and Midfielders (from 50 to 25; 50\%). This indicates that there are more differences among the Forwards than the other positions.

Finally, we can calculate the metatechnology ratio (see [2]) in the different positions:

Table 5

Metatechnology ratio

\begin{tabular}{|l|l|}
\hline \multicolumn{1}{|c|}{ Position } & MTR \\
\hline DEFENDER & 0.9806 \\
\hline MIDFIELDERS & 0.9785 \\
\hline FORWARDS & 0.9768 \\
\hline
\end{tabular}

Source: Own elaboration.

In the Table 5, the MTR shows when far from the global frontier is every group frontier, and these ratios confirm that the greatest technological differences are found among the Forwards. This result contrasts with the widely held view that Forwards are the most efficient players and is also consistent with the results published by Tiedemann et al. (2011). In soccer, in general, the attack actions are initiated in to defense, continue with the midfield and just them in the opposite field. Therefore, the inefficiencies of each positions are 
accumulated towards the more advanced positions. Hence, the inefficiency of the Defenders is moved to Midfielders, which along with own inefficiency is moved to Forwards. For this reason Forwards is the group with greater MTR.

The reduction in efficiency between the group and metrafrontier, affected major players, both Spanish and foreign.

Let's then consider the behaviour of efficient players in different groups.

\subsection{Spanish players compared to foreign players:}

Most Defensive and Midfield players are Spanish (S), while the opposite occurs with Forwards where almost 60 percent of the efficient Forwards are foreign (F). These Forwards include two of the most recognisable players in the soccer world: Messi and Cristiano Ronaldo.

Table 6

Spanish players versus foreign players

\begin{tabular}{|l|c|c|c|c|}
\hline \multicolumn{1}{|c|}{ Position } & Number Eff & S & F & \% S/N \\
\hline DEFENDER & 24 & 13 & 11 & 54.2 \\
\hline MIDFIELDERS & 25 & 19 & 6 & 76.0 \\
\hline FORWARDS & 17 & 7 & 10 & 41.2 \\
\hline ALL & 66 & 39 & 27 & \\
\hline
\end{tabular}

Source: Own elaboration.

\subsection{Spanish international players:}

We examined how many of the efficient Spanish players had played for the national team last year. Of the the 39 Spanish players (S), 12 are internationals (I), distributed as follows.

Table 7

Spanish International players

\begin{tabular}{|l|c|c|c|}
\hline \multicolumn{1}{|c|}{ Position } & S & F & \% S/N \\
\hline DEFENDER & 13 & 5 & 38.5 \\
\hline MIDFIELDERS & 19 & 4 & 21.1 \\
\hline FORWARDS & 7 & 3 & 42.9 \\
\hline ALL & 39 & 12 & 30.8 \\
\hline
\end{tabular}

Source: Own elaboration. 
Once again, defenders are the majority when compared with the other positions. The most efficient players in this group are:

- Defenders: Sergio Ramos, Puyol, Pique, Albiol and Capdevila.

- Midfielders: Xavi, Xabi Alonso, Busquets and Javi Martinez.

- Forwards: Pedro, Villa and Llorente

This selection is very nearly the team that won the 2010 World Cup. The only players missing are Casillas (goalkeepers are not included in the study) and Iniesta (who suffered numerous injuries during the season).

\subsection{Teams}

Another approach to analysing the good performance of efficient players is to look at their participation in the 20 teams of the Spanish first division.

By noting their team and the points scored by each team during the 2009/10 season, we obtain the results showed in Table 8 .

Table 8 reveals that most of the players (11) belong to one of the two teams that achieved the most points, namely, Barcelona and Real Madrid.

The correlation coefficient between the two series (number of efficient players per team and points won by each team) is 0.928 . This very high figure confirms the existence of a direct relationship between the number of efficient players and the number of points won in the league.

Table 8

Efficient players and final points by team

\begin{tabular}{|l|c|c|}
\hline \multicolumn{1}{|c|}{ TEAM } & Players & Points \\
\hline Almería & 3 & 42 \\
\hline At. Madrid & 2 & 47 \\
\hline Athletic Club & 3 & 54 \\
\hline Barcelona & 11 & 99 \\
\hline Deportivo de La Coruña & 2 & 47 \\
\hline Espanyol & 0 & 44 \\
\hline Getafe & 3 & 58 \\
\hline Málaga & 1 & 37 \\
\hline Mallorca & 5 & 62 \\
\hline Osasuna & 3 & 43 \\
\hline Racing de Santander & 0 & 39 \\
\hline Real Madrid & 11 & 96 \\
\hline Sevilla & 3 & 63 \\
\hline Sporting de Gijón & 1 & 40 \\
\hline Tenerife & 3 & 36 \\
\hline
\end{tabular}


Table 8 (continue)

Efficient players and final points by team

\begin{tabular}{|l|c|c|}
\hline \multicolumn{1}{|c|}{ TEAM } & Players & Points \\
\hline Valencia & 6 & 71 \\
\hline Valladolid & 0 & 36 \\
\hline Villarreal & 6 & 56 \\
\hline Xerez & 1 & 34 \\
\hline Zaragoza & 2 & 41 \\
\hline TOTAL / CORREL. INDEX & 66 & 0.928 \\
\hline
\end{tabular}

Source: Own elaboration.

\section{CONCLUSIONS}

The aim of this paper was to assess soccer players using the metafrontier methodology. We have applied it to performance data from the most recent season in the Spanish soccer league (2009/10). For our purposes, we have considered three basic positions: Defence, Midfield, and Forward. The obtained results reveal that Defenders and Midfielders are more efficient than Forwards, and this is contrary to the widespread opinion that Forwards perform better than other players. This is due to the Forwards accumulate inefficiency of Midfields, and these in turn of the Defenders.

Moreover, an examination of the behavior of groups such as Spanish and foreign players, and international players and club teams, leads us to the following conclusions: Spanish players are more efficient than foreign players; all of the Spanish World Cup winning team are efficient; and the highest ranking club teams are those that have the greatest number of efficient players.

The methodology and the empirical approach developed in this paper shows how the assessment of the efficiency of individual players is an useful tool to support decision in the management of group sports.

\section{REFERENCES}

ALP, I. (2006). Performance evaluation of goalkeepers of the world cup. Gazi University Journal of Science 19(2):119-125.

BONILLA, M. T.; CASASÚS, A.; MEDAL, A. and SALA R. (2002). Traffic in Spanish ports: an efficiency analysis, International Journal of Transport Economics 29, 215-230. 
BOSCA, J. E.; LIERN V., MARTINEZ, A. and SALA, R. (2009). Increasing offensive or defensive efficiency? An analysis of Italian and Spanish football. Omega, International Journal of Management Science 37:63-78.

DAWSON, P.; DOBSON, S. and GERRARD, B. (2000). Stochastic frontiers and the temporal structure of managerial efficiency in English soccer. Journal of Sports Economics 1(4):341-362.

ESPITIA-ESCUER M. and GARCIA-CEBRIAN, L.I. (2006). Performance in sports teams. Results and potential in the Professional Soccer League in Spain. Management Decision 44(8):1020-1030.

FÄRE, R. and PRIMONT, D. (1995). Multi-Output Prodution and Dualiy: Theory and Appliactions. Kluwer Academic Publisher. Boston

GONZÁLEZ-GÓMEZ, F. and PICAZO-TADEO, A.J., 2010. Can we be satisfied with our football team? Evidence from Spanish professional football. Journal of Sports Economics, 11(4), 418-442.

KERN M. and SÜSSMUTH, B. (2005) Managerial efficiency in German Top League Soccer: an econometric analysis of club performances on and off the pitch. Germen Economic Review 6(4):485-506.

LUCIFORA, C. and SIMMONS, R. (2003). Superstar effects in sport: Evidence from Italian Soccer. Journal of Sports Economics 4: 35-55.

O'DONNELL, C. J.; RAO, D. S. P. and BATTESSE, G. E. (2008). Metafrontier frameworks for the study of firm-level efficiencies and technology ratios. Empirical Economics 34(2): 231-255

GECASport is now known as Opta España. C. General Rodrigo 6, $6^{\circ} \mathrm{lzq}$, 28003, Madrid. http://www.sdifutbol.com/optaspain.htm

PAPAHRISTODOULOU, C. (2007). The relative efficiency of UEFA Champions League scorers. MPRA Paper Number 4943. http://mpra.ub.unimuenchen.de/4943/

RIERA, A.: RIPOLL, A.M. and JUANEDA, C. N. (2011): Efficiency and Seasonality in the Balearic Hospitality Industry Estudios de Economía Aplicada , 29 (3), 845-862.

SALA-GARRIDO, R.; LIERN, V.; MARTINEZ, A. and BOSCÁ, J. E. (2009). Analysis an evolution of efficiency in the Spanish Soccer League (2000/012007/08). Journal of Quantitative Analysis in Sports 5(1/3):1-22.

SALA-GARRIDO, R.; MOLINOS-SENANTE, M. and HERNÁNDEZ-SANCHO, F. (2011). Comparing the efficiency of wastewater treatment technologies through a DEA metafrontier model. Chemical Engineering Journal. 179: 766772.

TIEDEMANN T.; FRANCKSEN, T. and LATACZ-LOHMANN, U. (2011). Assessing the performance of German Bundesliga football players: A non-parametric metafrontier approach. CEJOR 18 (2), 1-17. 